Swarthmore College

Works

Fall 2017

\title{
Introduction To Spanish Literature/Introducción A La Literatura Española (SPAN 22) Syllabus
}

\author{
Eli Cohen \\ Swarthmore College, ecohen3@swarthmore.edu
}

Follow this and additional works at: https://works.swarthmore.edu/dev-dhgrants

Part of the Spanish and Portuguese Language and Literature Commons

\section{Recommended Citation \\ Eli Cohen. (2017). "Introduction To Spanish Literature/Introducción A La Literatura Española (SPAN 22) Syllabus". Introduction To Spanish Literature/Introducción A La Literatura Española. DOI: 10.24968/ 2476-2458.dhgrants.9 \\ https://works.swarthmore.edu/dev-dhgrants/9}

\section{(c) (i)}

This work is licensed under a Creative Commons Attribution 4.0 License.

This work is brought to you for free by Swarthmore College Libraries' Works. It has been accepted for inclusion in Digital Humanities Curricular Development by an authorized administrator of Works. For more information, please contactmyworks@swarthmore.edu. 


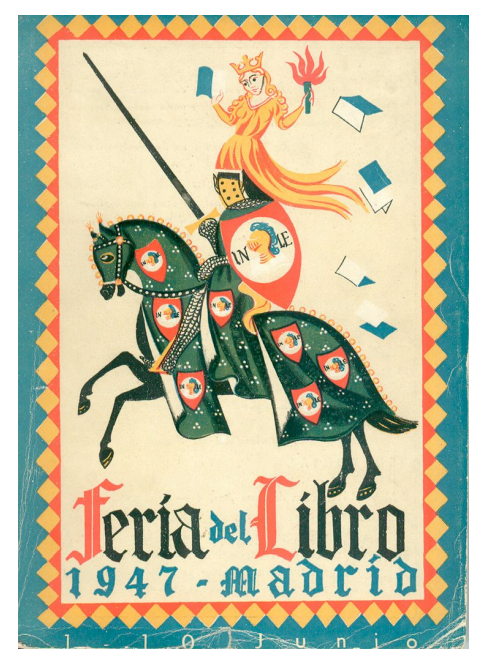

\author{
Otoño 2017 \\ Span $022[W]$ \\ Introducción a la \\ literatura española
}

Profesor Eli Cohen

Kohlberg 323

Email: ecohen3@swarthmore.edu

Tel.: (610) 957-6099
Horas de oficina: T/TH 10:00-11:00 PM

o por cita previa (www.swarthmore.edu/officehours)

Descripción del curso: Este curso es una introducción panorámica a la literatura española desde la Edad Media hasta nuestros días. Los estudiantes leerán y analizarán, de forma oral y escrita, textos poéticos, narrativos, dramáticos, fílmicos y digitales, teniendo siempre en cuenta el contexto histórico y cultural en que se produce cada uno. Tanto en las discusiones de clase como en los trabajos escritos, se pondrá especial énfasis en el análisis literario. A través de la reflexión tanto escrita como en clase, se espera que el alumno desarrolle las habilidades de un lector atento y estudioso de la literatura. Además del análisis crítico, los estudiantes desarrollarán dos proyectos digitales que consistirán en una cronología visual-textual del panorama de la literatura española y una exploración digital de diferentes puntos de contacto de las letras españolas de todos los siglos.

\title{
¡Ojo! Curso enseñado en español.
}

Metódos: se enfatizará la discusión en clase y por eso la participación de los estudiantes será un aspecto fundamental del curso. La participación consistirá en la presencia atenta y la contribución activa a las conversaciones y actividades realizadas en clase. Por lo tanto, la asistencia es crucial.

Metas generales del curso: los estudiantes en este curso (1) profundizarán en su conocimiento de la literatura y cultura española a través de la lectura de algunos de sus obras más representativas; (2) continuarán desarrollando sus habilidades lingüísticas con el uso del español en sus diversas dimensiones (comunicación oral, lectura, escritura); (3) aumentarán sus capacidades críticas a través de la lectura detenida y minuciosa ('close reading'), el diálogo sostenido y la argumentación razonada. Además, al ser un curso de redacción (W), los estudiantes (4) perfeccionarán sus destrezas de escritura analítica. 


\section{Objetivos de aprendizaje particulares para los estudiantes:}

1. leer una selección de obras representativas de la historia literaria española y desarrollar un conocimiento detallado de los textos y sus contextos

2. demostrar una capacidad de interpretar y analizar un texto literario dentro de sus contextos históricos y teóricos

3. además de estar expuestos al castellano en las clases y las lecturas, los estudiantes usarán el idioma en sus conversaciones en clase y en sus trabajos escritos, desarrollando también un conocimiento general de la evolución del castellano literario a lo largo de su historia

4. superar la reacción subjetiva y construir una interpretación fundada en evidencia textual

5. demostrar la capacidad de desarrollar una tesis clara y concisa y de articular un argumento metódico

6. mejorar su escritura y argumentación a través de la práctica de autoedición y de edición en pareja.

7. familiarizarse con diferentes métodos de acercarse a una obra literaria, de realizar un análisis del mismo, y de expresar y presentar ese análisis. Esos métodos incluirán los de la lectura atenta y detenida (close reading), la lectura contextualizada, el uso de herramientas digitales, la expresión y argumentación oral y escrita, y la presentación digital de diversos medios y de los resultados de investigación.

\section{Textos obligatorios:}

Todos los textos del curso estarán disponibles en Moodle

Textos y recursos recomendados:

-MLA Handbook for Writers of Research Papers (Modern Language Association; ISBN

9781603290241), o en Internet: https://owl.english.purdue.edu/owl/resource/747/1/

-Diccionario monolingüe de la Real Academia Española: www.rae.es/drae

-Diccionario de sinónimos: http://www.elmundo.es/diccionarios/

-Diccionario multilingüe: www.wordreference.com

\section{Evaluación:}

-Participación

-Hojas de reacción (5) $\quad 15 \%$

-Presentaciones $10 \%$

-Contribución a los proyectos digitales $\quad 15 \%$

-Examen parcial $\quad 10 \%$

-Ensayos breves (2; 3-4 págs.) 20\%

-Trabajo final (8-10 págs.) 15\% 


\section{Participación (15\%):}

La participación es fundamental en esta clase y, por lo tanto, la asistencia es obligatoria. La participación en clase consiste en la intervención activa en las discusiones del grupo. Esas intervenciones deben reflejar la preparación anterior, ya que el aula es el lugar para compartir las experiencias de cada individuo con los textos. Por eso se espera que todos hayan leído y pensado sobre los textos, las preguntas de discusión y las tareas asignadas, y que hayan formulado sus propias preguntas, dudas o comentarios antes de clase. Finalmente, se espera que los alumnos demuestren un desarrollo en la expresión (oral y escrita) de sus ideas y en su trabajo analítico.

\section{Hojas de reacción (15\%):}

El/la estudiante deberá escribir 1 o 2 páginas de reflexión crítica sobre las lecturas. En ocasiones se tratará de responder a una pregunta hecha por el profesor. No se trata de resumir el argumento de la lectura sino de sintetizar y de analizar los temas del texto o la película. La gramática no se tendrá en cuenta en estos escritos, sin embargo, la organización será importante. La hoja de reacción puede ser el origen del tema de un ensayo; sin embargo, el ensayo no puede ser una copia de la hoja de reacción.

\section{Presentaciones (10\%):}

Cada alumno presentará sobre uno de los textos. Las presentaciones serán de unos 7-10 minutos y se realizarán en español. Se ofrecerá más información sobre las presentaciones en las primeras semanas del curso.

\section{Contribución a los proyectos digitales $(15 \%)$ :}

A lo largo del curso, los estudiantes desarrollarán un proyecto digital en el que crearán una cronología visual y textual de las letras españolas desde sus principios hasta la actualidad. El segundo proyecto digital estará vinculado a las presentaciones de los estudiantes y al ensayo final e incorporará imágenes asociadas con el contexto histórico de las obras leídas, imágenes textuales y comentarios críticos de los estudiantes. Se ofrecerá más información sobre los proyectos digitales en las primeras semanas del curso.

\section{Examen parcial (10\%):}

Habrá dos exámenes parciales (uno a mitad del semestre y el otro al final del semestre) sobre los textos, los autores y las épocas literarias e históricas presentados en el curso.

\section{Trabajos escritos/ensayos:}

Los alumnos escribirán dos ensayos breves (20\%), de 3-4 páginas de extensión. El primer trabajo será sobre un texto de las primeras 4 semanas, elegido por el/la estudiante, y presentará una lectura minuciosa (close reading) de un fragmento o episodio del texto. El segundo trabajo ofrecerá una lectura de uno de los textos de la séptima u octava semana del semestre (la España moderna y la crisis del 98).

El ensayo final (15\%): de 6-8 páginas, presentará un proyecto de investigación individual sobre un(os) text(os) de la última parte del curso (de Federico García Lorca a Manuel Rivas).

Se repartirán instrucciones detalladas sobre cada ensayo según se acerquen sus fechas límites. 
Este curso tiene un enfoque en la redacción. Por eso, tendremos varias sesiones en las que nos centraremos en los ensayos, en su desarrollo, su revisión y su edición. Además, tendremos un WA asociado con el curso y con quien los alumnos trabajarán a lo largo del semestre.

No se aceptará la entrega tarde del trabajo del curso a no ser que haya habido una emergencia médica o familiar. En caso de que se den tales circunstancias, el/la estudiante debe ponerse en contacto con el profesor tan pronto como sea posible.

Se permiten dos ausencias no escusadas. Si un/a estudiante es ausente de la clase más de dos veces sin escusa válida, cada ausencia, a partir de la tercera, tendrá un efecto negativo equivalente a 1 punto de la nota final. Si se dan más de cuatro casos (dos semanas) de ausencia no justificada, el profesor reserva el derecho de suspender al/a la estudiante en cuestión.

- Hay tres tipos de ausencia justificada: una emergencia médica o familiar; una competición deportiva de la universidad; una fiesta (holiday) religiosa. En caso de faltar a una clase, el/la estudiante proveerá la documentación adecuada y tiene la responsabilidad de entregar cualquier tarea asignada para el día en cuestión.

- Según la política de la universidad y el Manual del/de la estudiante atleta (StudentAthlete Manual), el/la estudiante que pueda tener conflicto de horario entre clases y competiciones deportivas debe entregar al profesor una copia de su horario de competiciones, incluyendo la hora de salida o del partido, al principio del semestre.

\section{Honestidad académica:}

Se espera que los/las estudiantes de este curso cumplan con el Swarthmore College Student Handbook y con las reglas sobre la honestidad académica que allí se enumeran. Además, el profesor tiene la política inmediata de que cualquier estudiante que se considera que haya plagiado o copiado, según la evidencia disponible, en cualquier trabajo asignado de forma individual, no recibirá crédito por el curso. Los alumnos deben distinguir en todo momento entre sus propias ideas y palabras y las de otras personas. El uso de cualquier fuente debe ser indicado utilizando el sistema del MLA (Modern Language Association) para las citas.

\section{El trabajo en el aula vs. el trabajo en casa:}

Las discusiones en clase serán fundamentalmente colaborativas, pero todo el trabajo realizado fuera de clase debe ser realizado por cada alumno de modo individual (si no se pide expresamente el trabajo en grupo).

\section{Acomodaciones:}

If you believe that you need accommodations for a disability, please contact Leslie Hempling in the Office of Student Disability Services (Parrish 113) or email

lhempli1@swarthmore.edu arrange an appointment to discuss your needs. As appropriate, she will issue students with documented disabilities a formal Accommodations Letter. Since accommodations require early planning and are not retroactive, please contact her as soon as possible. For details about the accommodations process, visit the Student Disability Service Website at http://www.swarthmore.edu/academic-advisingsupport/welcome-to-student-disability-service. You are also welcome to contact me [the faculty member] privately to discuss your academic needs. However, all disability-related accommodations must be arranged through the Office of Student Disability Services. 


\section{Calendario de clases, lecturas y tareas:*}

*Syllabus subject to change; all modifications or alterations will be announced in advance.

\section{Introducción}

Martes 5/9:

Introducción al curso; repaso de los requisitos, metas y objetivos del curso; introducción al contexto histórico; historia y literatura: problemas, perspectivas y puntos de partida. La lectura minuciosa/detenida y el análisis literario.

Jueves 7/9:

Orígenes de la literatura española; hibridez cultural y literaria: el legado del pasado visigodo y de Al-Andalus; formas de transgresión literaria: las jarchas y los romances de don Rodrigo.

Lectura: Menocal, "A Brief History of a First-Rate Place" Lobanyi, Spanish Literature: A Very Short Introduction (selección)

\section{De los orígenes a la temprana modernidad}

Martes 12/9:

Jueves 14/9:

Martes 19/9:
La literatura medieval: orígenes

Lectura: $\quad$ Anónimo, El poema del Cid (sel.) Lobanyi, Spanish Literature (sel.)

La literatura medieval: la narrativa

Lectura: $\quad$ Don Juan Manuel, El conde Lucanor (sel.)

Guía de lectura

Introducción al proyecto digital: objetivos y herramientas

Los albores de la modernidad

Lectura: $\quad$ Fernando de Rojas, La Celestina (sel.)

Guía de lectura 
Lectura: Anónimo, Lazarillo de Tormes (sel.) Guía de lectura

Martes 26/9:

La poesía renacentista y barroca

Lectura: Garcilaso de la Vega, Góngora y Quevedo, poemas (sel.)

Guía de lectura

Proyecto digital: el imaginario renacentista

Jueves 28/9:

El teatro del Siglo de Oro

Lectura: Lope de Vega, Fuenteovejuna, Acto I

Guía de lectura

Martes 3/10:

Lectura: Lope de Vega, Fuenteovejuna, Actos II y III Guía de lectura

Jueves 5/10:

El teatro del Siglo de Oro: el mito de don Juan

Cine: $\quad$ Tirso de Molina, El burlador de Sevilla Guía de lectura

Taller de redacción/revisión en parejas

Borrador del primer ensayo

Proyecto digital: los teatros del Siglo de Oro

Martes 10/10:

La narrativa del Siglo de Oro: hacia la novela moderna

Lectura: Cervantes, El celoso extremeño Guía de lectura

Jueves 12/10: [ [Por determinar] 


\section{La España moderna}

Martes 24/10:

La España moderna: Ilustración y Romanticismo (siglo XVIII)

Lectura: Cadalso, Cartas marruecas (sel.)

José de Espronceda, poemas (sel.)

Gustavo Adolfo Bécquer, poemas (sel.)

Rosalía de Castro, poemas (sel.)

Guía de lectura

Proyecto digital: el romanticismo y lo sublime

$---$

Jueves 26/10:

El realismo español

Lectura: Clarín, "Adiós Cordera"

Emilia Pardo Bazán, "El encaje roto"

Guía de lectura

Proyecto digital: el realismo

Martes 31/10: $\quad$ El Modernismo

Lectura: Antonio Machado, poemas (sel.)

Guía de lectura

>>>Entregar Examen Parcial $<<<$

De la crisis del 98 hasta la España democrática

Jueves 2/11: $\quad$ El teatro moderno

Lectura: Federico García Lorca, La casa de Bernarda Alba, Acto I

Guía de lectura

Taller de redacción/revisión en parejas

Borrador del segundo ensayo

Martes 7/11: $\quad$ Lectura: $\quad$ Federico García Lorca, La casa de Bernarda Alba, Actos II y III

Guía de lectura 
Jueves 9/11:

Lectura: Federico García Lorca, poemas (sel.)

Guía de lectura

Proyecto digital: la Guerra Civil Española y la literatura

Martes 14/11:

La posguerra I

Lectura: Carmen Martín Gaite, "Las ataduras"

Guía de lectura

>>>Entregar segundo trabajo escrito $<<<$

Jueves 16/11: $\quad$ La posguerra II

Lectura: Luis Cernuda, poemas (sel.)

Guía de lectura

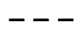

Martes 21/11: $\quad$ La posguerra III

Lectura: Carme Riera, "Te entrego, amor, la mar como una ofrenda"

Guía de lectura

Proyecto digital: la topografía social de la posguerra

***Día de Acción de Gracias***

Martes 28/11:

La mirada hacia el pasado y la memoria histórica

Lectura: Manuel Rivas, "La lengua de las mariposas"

Cine: $\quad$ La lengua de las mariposas

Guía de lectura

Proyecto digital: literatura y cine 


\section{La literatura contemporánea}

Jueves 30/11: $\quad$ La posmodernidad

Lectura: Maruja Torres, "Desaparecida"

Guía de lectura

Martes 5/12: $\quad$ Hacia el futuro: nuevas formas literarias

Lectura: Benjamín Escalonilla Godayol S I N F E R I D A D

Juan José Díez, Don Juan en la frontera del espíritu

Félix Remirez, Trincheras de Mequinenza

Guía de lectura

Proyecto digital: El imaginario literario en la cultura española (introducción y construcción del espacio Scalar)

Jueves $7 / 12$ :

Taller de redacción/revisión en parejas

Borrador del tercer ensayo

Proyecto digital: El imaginario literario en la cultura española (construcción del espacio - Scalar)

Martes 12/12:

Proyecto digital: El imaginario literario en la cultura española (finalización de la página web - Scalar)

Entregar ensayo final: fecha por confirmar. 